\title{
HAS CO-MOVEMENT DYNAMICS IN BRAZIL, RUSSIA, INDIA, CHINA AND SOUTH AFRICA (BRICS) MARKETS CHANGED AFTER GLOBAL FINANCIAL CRISIS? NEW EVIDENCE FROM WAVELET ANALYSIS
}

\author{
M. Kannadhasan ${ }^{1 *}$ and Debojyoti Das ${ }^{2}$ \\ ${ }^{1}$ Indian Institute of Management Raipur, Atal Nagar, P. O. - Kurru (Abhanpur) \\ Raipur, Chhattisgarh, - 493 661, India \\ ${ }^{2}$ Woxsen School of Business, Hydrabad, Telangana 502345, India \\ ${ }^{*}$ Corresponding author: mkdhasan@iimraipur.ac.in
}

\begin{abstract}
We investigate the changes in the co-movement dynamics in the stock market returns of Brazil, Russia, India, China and South Africa (BRICS) with that of US during pre and post-global financial crisis (GFC). The stock returns of BRICS and the US markets over the period of 1999-2016 are analysed using wavelet transformation, with equal time phase of eight years on both sides of GFC. We find the existence of co-movement at both high and low frequencies. In addition, the contagion effect is also noted around the GFC year 2008. Further we also report that despite the high correlation of BRICS portfolio, it facilitates asset diversification benefits in the medium run. Finally, there is significant changes in correlation dynamics for Russia and China during post-GFC period, whereas the multiple correlations dynamics amongst BRICS markets remain unchanged.
\end{abstract}

Keywords: co-movement, wavelet, global financial crisis, BRICS

Publication date: 15 August 2019

To cite this article: Kannadhasan, M., \& Das, D. (2019). Has co-movement dynamics in BRICS markets changed after global financial crisis? New evidence from wavelet analysis. Asian Academy of Management Journal of Accounting and Finance, 15(1), 1-25. https://doi.org/10.21315/ aamjaf2019.15.1.1

To link to this article: https://doi.org/10.21315/aamjaf2019.15.1.1

(C) Asian Academy of Management and Penerbit Universiti Sains Malaysia, 2019. This work is licensed under the terms of the Creative Commons Attribution (CC BY) (http://creativecommons. org/licenses/by/4.0/). 


\section{INTRODUCTION}

To date, research on international portfolio diversification literature has addressed several important questions. Among the ones that have received the greatest attention are as follows: Do the international markets interdependent and what role do emerging market play in attaining the diversification benefits? Addressing these questions are important for investors' asset allocation and risk management. Although the extant literature opined that interdependence among the markets has increased since mid-1990s (Brooks \& Del Negro, 2004; Pukthuanthong \& Roll, 2009), there has been no clarity on this interdependence, whether it is permanent or temporary in nature. Ayuso and Blanco (2001) opined that the interdependence is permanent, which is due to an increasing importance of global factors in relation to country specific factors (Hargis \& Mei, 2006). Conversely, Brooks and Del Negro (2004) found that this interdependence is temporary by linking the stock market bubble during 1990s. Numerous studies investigated the comovement among the developed markets (Graham \& Nikkinen, 2011; Karolyi \& Stulz, 1996; Ranta, 2013; Rua \& Nunes, 2009) and emerging markets (Aloui \& Hkiri, 2014; Arouri, Bellalah, \& Nguyen, 2010; Boako \& Alagidede, 2017; Dima, Dima, \& Barna, 2014; Kiviaho, Nikkinen, Piljak, \& Rothovius, 2014). In the recent years, the studies investigated the relationship between developed and emerging markets (Baruník, Vácha, \& Krištoufek, 2011; Das, Kannadhasan, \& Goyal, 2016; Graham, Kiviaho, \& Nikkinen, 2012; Lehkonen \& Heimonen, 2014; Zhang, Li, \& Yu, 2013).

Researchers, financial experts, investors, economist, and policy makers have been placing a lot of emphasis on understanding the co-movement of stock price/return among the emerging equity markets in relation to developed equity markets for the past two decades. It is because of the trend towards an internationalisation of stock exchanges since 1990s (Francis, Hasan, \& Sun, 2008; Hasan, Schmiedel, \& Song, 2012) and more importantly, the higher average returns and lower correlation with developed markets (Bekaert \& Harvey, 1997). Since then, numerous studies have documented the importance of co-movements between these two classes of markets both theoretically and empirically. For instance, Longin and Solnik (1995), Chan, Gup and Pan (1997), Berben and Jansen (2005), and many other studies have examined the level of integration between markets. Having knowledge on the level of co-movements among the different stocks would be useful for investors in asset allocation and risk management (Aloui \& Hkiri, 2014; Rua \& Nunes, 2009).

The impact of ongoing changes in the emerging markets, for example, China equity market attracted the interest of investors once joined in World 
Trade Organization in 2001 (Zhang \& Li, 2014) on the level of integration with developed market, thereby, benefits of international portfolio diversification and risk management is the other crucial area of interest for the scholars. According to investment theory, there is an inverse relationship between correlation and diversification benefits. There is a higher incentive in investing across countries rather than investing across industries domestically (Brooks \& Del Negro, 2004). The diversification benefits depend on the correlation among the stock markets (Longin \& Solnik, 1995). As the correlation is time-varying phenomena (Karolyi $\&$ Stulz, 2003), studies have examined the diversification benefits by computing time-varying correlation (Brooks \& Del Negro, 2004; Gupta \& Donleavy, 2009; Syriopoulos, 2007; Syriopoulos \& Roumpis, 2009; Zhang et al., 2013). For instance, Brooks and Negro (2004) found that the correlation has been increasing between the developed stock markets, which reduces the diversification benefits. Similarly, the potential benefits have changed in other markets too (Schwebach, Olienyk, \& Zumwalt, 2002). Besides, scholars have analysed the impact of financial crisis on the co-movement of stock markets (Bekiros, 2014; Bianconi, Yoshino, \& De Sousa, 2013; Gklezakou \& Mylonakis, 2009; Yang, Kolari, \& Min, 2003), thereby, benefits of diversification. Those studies found the financial crisis affected the correlation and changed the level of diversification benefits (Das et al., 2018; Dewandaru et al., 2017, 2016; el Alaoui et al., 2015; Masih et al., 2010; Najeeb et al., 2015; Saiti \& Masih, 2014). However, a very few studies have examined the co-movement between BRICS and developed market (Lehkonen \& Heimonen, 2014; Zhang et al., 2013).

Brazil, Russia, India, China and South Africa (BRICS) have been receiving considerable attention among the emerging economies (Bianconi et al., 2013). The reasons are: (a) Brazil, Russia, India and China (BRIC) are considered among top four countries in the world measured in terms of purchasing power parity adjusted to nominal gross domestic product (GDP) as part of BRICS. (b) Mark Mobius (Executive director of Templeton Emerging Markets Group) pointed out that "The worries and uncertainty will likely continue to create some angst in the global market, which could spill over into emerging markets, including BRICS countries". This necessitates us to examine the co-movement of stock returns between the Brazil, Russia, India, China and South-Africa (henceforth, BRICS) markets and developed market. We also investigate whether the co-movement pattern has been changed during post-global financial crisis (GFC) period or not. Studies in the recent past have attempted to unveil the time-varying correlations between developed (US and Europe) and emerging BRICS markets (Zhang et al., 2013). The study (Zhang et al., 2013) concludes the financial crisis of 2008 has permanently changed the conditional correlational relationships of BRICS with the developed markets using the Dynamic Conditional Correlation-Generalized 
Autoregressive Conditional Heteroskedasticity (DCC-GARCH) techniques. The DCC-GARCH model is useful to captivate the time-varying correlations between two markets; however, this method fails to provide frequency-based correlation information. The frequency-based information is extremely relevant to decide the term of investment (long, medium or short). Thus, a combined time-frequency based stock co-movement analysis becomes inevitable to devise diversification strategies. On this note, Aloui and Hkiri (2014) argue that limited attention has been paid to analyse co-movement phenomenon in a time-frequency domain. Nevertheless, some recent studies have relied upon time-frequency analysis to deepen the understanding of stock market co-movements using wavelet-based methods (Aloui \& Hkiri, 2014; Baruník et al., 2011; Boako \& Alagidede, 2017; Das et al., 2016; Graham et al., 2012; Graham \& Nikkinen, 2011; Kiviaho et al., 2014; Lehkonen \& Heimonen, 2014; Rua \& Nunes, 2009) among others. The wavelet-based techniques are superior to traditional econometric methods on the count of its ability to derive frequency-related information (Reboredo \& Rivera-Castro, 2013). Therefore, we used namely, wavelet coherence approach that allow us to assess short-run and long-run diversification benefits in both time and frequency domain. We contribute to the literature on co-movement and contagion in the following ways: Firstly, we find mostly positive co-movements between BRICS and US markets. Secondly, we show that the co-movements are intense at lower frequencies during the GFC period which could be attributed to the contagious behaviour of the markets. Thirdly, we report significant changes in correlation patterns in the post GFC era for Russia and China, whereas the multiple correlations dynamics amongst BRICS markets remains unchanged.

\section{ESTIMATION METHODOLOGY}

This section briefly describes the estimation strategies used in the study. ${ }^{1}$ This study employs three wavelet-based methodologies described as follows:

\section{Wavelet Coherence}

This sub-section explains the fundamental concepts of Continuous Wavelet Transform (CWT). The CWT of a time-series $x(t)$ is expressed as:

$W x(\tau, s)=\int_{-\infty}^{\infty} x(t) \tilde{\psi}_{v, s}^{*}(t) d t, s, \tau \in \mathbb{R}, s \neq 0$

where $x(t) \tilde{y}_{t, s}^{*}(t)$ is the complex conjugate of the analysing function $\tilde{\psi}_{\tau, \mathrm{s}}(t)$. The function of time $x(t)$ is transformed into a signal by the analysing function. The wavelet transform output is a $|2 \times 2|$ matrix of coefficient, which 
is identified by their scale and translation. The translation parameter is denoted by $\tau$, which represents its location. The length of the wavelet is determined by scaling factor represented by $s . s, \tau \in \mathbb{R}$ since a wavelet is defined over a real axis and is a real or complex valued function. $\psi$ is the mother wavelet, defined as:

$$
\tilde{\psi}_{\tau, s}(t)=\frac{1}{\sqrt{|s|}} \psi\left(\frac{t-\tau}{s}\right)
$$

The type of mother wavelet considered was Morlet following its rich applicability in wavelet economics literature. The Morlet wavelet is given by:

$$
\psi^{M}(t)=\frac{1}{\pi^{1 / 4}} \cdot \exp \left(\mathrm{i} \omega_{0} t\right) \cdot \exp \left(-t^{2} / 2\right)
$$

The bivariate framework to observe the interaction between two timeseries $x(t)$ and $y(t)$ is called wavelet coherence. Cross wavelet transform is useful in this respect, defined as:

$$
W_{x y}(\tau, s)=W_{x}(\tau, s) W_{y}^{*}(\tau, s)
$$

The cross-wavelet transformation of two series $x(t)$ and $y(t)$ is defined with CWT as $W_{x}(\tau, s)$ and $W_{y}(\tau, s)$. The regions in time-frequency space, where the time-series of interest co-move can be identified by wavelet coherence. The squared wavelet coherence coefficient is given by:

$$
R_{x y}^{2}(\tau, s)=\frac{\left|S\left(s^{-1} W_{x y}(\tau, s)\right)\right|^{2}}{S\left(s^{-1}\left|W_{x}(\tau, s)\right|^{2}\right) S\left(s^{-1}\left|W_{y}(\tau, s)\right|^{2}\right)}
$$

where $S$ is the smoothing parameter achieved by convolution in both time and scale. The range of the squared wavelet coherence coefficients is $0 \leq R_{x y}^{2}(\tau, s) \leq 1$, signifying weaker (stronger) correlation for values closer to zero (one). The statistical significance is tested using Monte Carlo methods since the theoretical distribution of wavelet coherence is not known. To avoid the influence of errors on account of finite time-series with finite wavelets, the timeseries are padded with sufficient number of zeroes.

The observation of intervals in the oscillation (cycles) between two series under consideration is exhibited by wavelet coherence phase differences defined as:

$$
\phi_{\mathrm{xy}}(\tau, s)=\tan ^{-1}\left(\frac{\mathfrak{S}\left\{S\left(s^{-1} W_{x y}(\tau, s)\right)\right\}}{\Re\left\{S\left(s^{-1} W_{x y}(\tau, s)\right)\right\}}\right)
$$


where the real and imaginary part of cross-wavelet transform is denoted by $\mathfrak{R}($.$) and \mathfrak{I}($.$) respectively. The arrows in the wavelet coherence plots indicate$ the phase. The examined time-series tends to move together when zero phase difference is indicated. The phase (anti-phase) property of the concerned timeseries is signposted by arrows pointing right (left) indicating a positive (negative) correlation. The lead/lag relationship is designated by arrow trending upward (downward), which indicates first (second) series lead second (first) series by $90^{\circ}$.

\section{Wavelet Correlation}

The wavelet correlation is simply an interaction of the wavelet covariance of two time-series $\{x(t), y(t)\}$ and the wavelet variance for $\{x(t)\}$ and $\{y(t)\}$. The Maximum Overlap Discrete Wavelet Transform (MODWT) estimator of the wavelet correlation is expressed as:

$$
\rho_{\mathrm{xy}}\left(\lambda_{j}\right)=\operatorname{Corr}\left(w_{i j t,} \tilde{w}_{i j t}\right)=\frac{\operatorname{Cov}\left(w_{i j t}, \tilde{w}_{i j t}\right)}{\operatorname{Var}\left(w_{i j t}\right) \operatorname{Var}\left(\tilde{w}_{i j t}\right)}
$$

$w_{j t}$ is the respective scale of wavelet coefficient $\lambda_{j}$ obtained by applying MODWT. The decomposition of the time-series using MODWT is done with Daubechies least asymmetric (LA) wavelet filter of length 8 . The index return series was decomposed into six details $\left[\left(D_{i 1}, \ldots, D_{i 6}\right)\right.$, see Table 1 for time interpretations] and one $V_{i 6}$ smooth component. The frequencies are denoted in terms of days.

Table 1

Time interpretation of different frequencies

\begin{tabular}{cc}
\hline Scale & Time-Frequency \\
\hline$D_{i 1}$ & $2-4$ weeks \\
$D_{i 2}$ & $4-8$ weeks \\
$D_{i 3}$ & $8-16$ weeks \\
$D_{i 4}$ & $16-32$ weeks \\
$D_{i 5}$ & $32-64$ weeks \\
$D_{i 6}$ & $64-128$ weeks \\
\hline
\end{tabular}




\section{Wavelet Multiple Correlation}

The wavelet multiple correlation (WMC) $\left(\phi x\left(\lambda_{j}\right)\right)$ is briefly described following Fernández-Macho (2012) as a single set of multiscale correlations calculated from $x(t)$. It is expressed as:

$$
\phi x\left(\lambda_{j}\right)=\operatorname{Corr}\left(w_{i j t,} \tilde{w}_{i j t}\right)=\frac{\operatorname{Cov}\left(w_{i j t} \tilde{w}_{i j t}\right)}{\sqrt{\operatorname{Var}\left(w_{i j t}\right) \operatorname{Var}\left(\tilde{w}_{i j t}\right)}}
$$

where, $x(t)$ is a multivariate stochastic process. $w_{j t}$ is the respective scale of wavelet coefficient $\lambda_{j}$ obtained by applying maximum overlap discrete wavelet transform (MODWT) to corresponding $x(i t)$ process.

\section{DATA}

Weekly country-specific index data from BOVESPA (Sao Paolo Stock Exchange, Brazil), MICEX Index (Moscow Stock Exchange, Russia), NIFTY Index (National Stock Exchange, India), Composite Index (Shanghai Stock Exchange, China) and Africa Top 40 Index (Johannesburg Stock Exchange, South Africa) is considered for the purpose of analysis after taking the respective log difference [Rt $\left.=\ln \left(P_{t}-P_{t-1}\right)\right]$ where $R_{t}$ is the index returns and $P_{t}$ is the index price at time $t$. Assuming the year 2008 to be the year of global financial meltdown, ${ }^{2}$ the study intends to analyse the data for a time-interval of eight years (approximately) both before and after the financial meltdown. Thus, the period of focus of our study essentially stands from January 1999 to September 2016 (890 observations). The stochastic properties of the data are described in Tables 2 and 3.

Table 2 details the stochastic properties of stock index returns. MICEX, Russia displays the highest spread between maximum and minimum daily returns. It also reports the highest mean returns against highest volatility. Among BRICS indices, China has the lowest mean return. Apart from South Africa, the returns are negatively skewed for the rest of the indices hinting at the high frequency negative returns in relation to positive returns. The Jarque-Bera test rejects the null hypothesis of normally distributed time series at 5\% level of significance. The data exhibits asymmetric spread since the Kurtosis values are farther away from zero with China having the most leptokurtic distribution. The Ljung-Box test statistics for Africa Top 40 index shows strong autocorrelation while the null hypothesis for data relating to the other indices cannot be rejected indicating random walk behaviour. Lastly, the results of the unit root test confirm that all the time-series under consideration fulfill the stationarity condition. The 
coefficients of the Augmented Dickey-Fuller (ADF) and Phillips Perron (PP) test are significant at $1 \%$ level indicating the fact that the underlying series are stationary. Table 3 reports the descriptive statistics of the discrete wavelet decomposed series. The mean returns are mostly positive for all the countries, except for Brazil and India at some scales. Besides the data series are positively skewed indicating more frequent occurrences of positive returns. In addition, excess kurtosis is also observed for all the countries at different scales signifying a leptokurtic distribution of stock returns.

Table 2

Descriptive statistics of stock index return time series

\begin{tabular}{lcccccc}
\hline & US & Brazil & Russia & India & China & South Africa \\
\hline Mean & 0.0005 & 0.0016 & 0.0033 & 0.0023 & 0.0010 & 0.0023 \\
Std. Dev. & 0.0298 & 0.0420 & 0.0580 & 0.0407 & 0.0495 & 0.0326 \\
Skewness & -7.190 & -3.025 & -9.572 & -8.288 & -11.964 & 0.117 \\
Kurtosis & 126.847 & 40.937 & 187.847 & 154.431 & 253.960 & 11.085 \\
Min & -0.527 & -0.550 & -1.133 & -0.755 & -1.044 & -0.183 \\
Max & 0.102 & 0.166 & 0.204 & 0.144 & 0.132 & 0.252 \\
JB & 511686.9 & 48579.4 & 1136771.7 & 763869.0 & 2091958.4 & 2153.7 \\
LB $Q(10)$ & 20.392 & 14.717 & 9.880 & 13.914 & 12.081 & 30.007 \\
LB $Q^{2}(10)$ & $(0.026)$ & $(0.143)$ & $(0.451)$ & $(0.177)$ & $(0.280)$ & $(0.001)$ \\
ADF & 1.676 & 1.683 & 0.554 & 0.321 & 0.120 & 71.679 \\
PP & $-32.998)$ & $(0.998)$ & $(0.999)$ & $(0.999)$ & $(0.999)$ & $(0.000)$ \\
\hline
\end{tabular}

Note: The critical value of Jarque-Bera (JB) test at 5\% level is 5.99. Ljung-Box (LB) test was performed taking lag of 10. The LB $Q$-stats is reported and p-values are reported in parentheses. ADF and PP denotes the Augmented Dickey Fuller and Philips Perron test respectively. *** denote significance at $1 \%$ level.

Figure 1 showcases the correlation coefficients among the sample indices that show high degree of relationship. Linear correlation fails to map the nonlinear dynamics in the data thus they may be interpreted cautiously (Andrieş, Ihnatov, \& Tiwari, 2016). Thus, to captivate the correlation subtleties over the study period the 12-months rolling correlations are mapped in Figure 2. 
Table 3

Descriptive statistics of stock index decomposed series

(a) US

\begin{tabular}{lcccccc}
\hline & $D_{i 1}$ & $D_{i 2}$ & $D_{i 3}$ & $D_{i 4}$ & $D_{i 5}$ & $D_{i 6}$ \\
\hline Mean & $8.4 \mathrm{E}-06$ & $4.3 \mathrm{E}-06$ & $9.6 \mathrm{E}-06$ & $2.0 \mathrm{E}-05$ & $3.3 \mathrm{E}-05$ & $4.2 \mathrm{E}-05$ \\
Std. Dev. & $4.8 \mathrm{E}-03$ & $2.3 \mathrm{E}-03$ & $1.4 \mathrm{E}-03$ & $9.8 \mathrm{E}-04$ & $1.1 \mathrm{E}-03$ & $8.1 \mathrm{E}-04$ \\
Max & $2.4 \mathrm{E}-02$ & $9.6 \mathrm{E}-03$ & $6.3 \mathrm{E}-03$ & $3.5 \mathrm{E}-03$ & $4.1 \mathrm{E}-03$ & $3.0 \mathrm{E}-03$ \\
Min & $-1.7 \mathrm{E}-02$ & $-9.4 \mathrm{E}-03$ & $-7.2 \mathrm{E}-03$ & $-3.2 \mathrm{E}-03$ & $-2.9 \mathrm{E}-03$ & $-1.6 \mathrm{E}-03$ \\
\hline
\end{tabular}

(b) Brazil

\begin{tabular}{|c|c|c|c|c|c|c|}
\hline & $D_{i 1}$ & $D_{i 2}$ & $D_{i 3}$ & $D_{i 4}$ & $D_{i 5}$ & $D_{i 6}$ \\
\hline Mean & $2.37 \mathrm{E}-11$ & $1.13 \mathrm{E}-10$ & $1.17 \mathrm{E}-10$ & $2.18 \mathrm{E}-10$ & $-2.76 \mathrm{E}-11$ & $4.54 \mathrm{E}-11$ \\
\hline Std. Dev. & $1.51 \mathrm{E}-02$ & 7.72E-03 & $4.55 \mathrm{E}-03$ & $3.79 \mathrm{E}-03$ & $3.47 \mathrm{E}-03$ & $2.92 \mathrm{E}-03$ \\
\hline Max & 7.97E-02 & $4.83 \mathrm{E}-02$ & $2.98 \mathrm{E}-02$ & $2.27 \mathrm{E}-02$ & $1.79 \mathrm{E}-02$ & $1.29 \mathrm{E}-02$ \\
\hline Min & $-8.11 \mathrm{E}-02$ & $-3.65 \mathrm{E}-02$ & $-2.02 \mathrm{E}-02$ & $-1.57 \mathrm{E}-02$ & $-1.10 \mathrm{E}-02$ & $-6.20 \mathrm{E}-03$ \\
\hline Skewness & $5.50 \mathrm{E}-01$ & 4.70E-01 & $6.28 \mathrm{E}-01$ & 7.97E-01 & $1.33 \mathrm{E}+00$ & $1.38 \mathrm{E}+00$ \\
\hline Kurtosis & $6.54 \mathrm{E}+00$ & $7.72 \mathrm{E}+00$ & $6.31 \mathrm{E}+00$ & $8.51 \mathrm{E}+00$ & $8.87 \mathrm{E}+00$ & $7.20 \mathrm{E}+00$ \\
\hline \multicolumn{7}{|l|}{ (c) Russia } \\
\hline & $D_{i 1}$ & $D_{i 2}$ & $D_{i 3}$ & $D_{i 4}$ & $D_{i 5}$ & $D_{i 6}$ \\
\hline Mean & $1.0 \mathrm{E}-12$ & $2.1 \mathrm{E}-10$ & $-5.2 \mathrm{E}-11$ & $1.5 \mathrm{E}-10$ & $6.0 \mathrm{E}-11$ & $1.7 \mathrm{E}-10$ \\
\hline Std. Dev. & $1.7 \mathrm{E}-02$ & 8.7E-03 & $6.4 \mathrm{E}-03$ & $5.5 \mathrm{E}-03$ & $4.8 \mathrm{E}-03$ & $4.6 \mathrm{E}-03$ \\
\hline Max & $1.4 \mathrm{E}-01$ & 4.3E-02 & $3.5 \mathrm{E}-02$ & $4.5 \mathrm{E}-02$ & $3.0 \mathrm{E}-02$ & $2.1 \mathrm{E}-02$ \\
\hline Min & $-1.4 \mathrm{E}-01$ & $-4.4 \mathrm{E}-02$ & $-3.5 \mathrm{E}-02$ & $-2.8 \mathrm{E}-02$ & $-1.7 \mathrm{E}-02$ & $-1.1 \mathrm{E}-02$ \\
\hline Skewness & 4.7E-01 & $3.4 \mathrm{E}-01$ & $3.3 \mathrm{E}-01$ & $2.1 \mathrm{E}+00$ & $1.9 \mathrm{E}+00$ & $1.4 \mathrm{E}+00$ \\
\hline Kurtosis & $1.3 \mathrm{E}+01$ & $5.4 \mathrm{E}+00$ & $8.9 \mathrm{E}+00$ & $2.3 \mathrm{E}+01$ & $1.4 \mathrm{E}+01$ & $7.6 \mathrm{E}+00$ \\
\hline \multicolumn{7}{|l|}{ (d) India } \\
\hline & $D_{i 1}$ & $D_{i 2}$ & $D_{i 3}$ & $D_{i 4}$ & $D_{i 5}$ & $D_{i 6}$ \\
\hline Mean & $-9 \mathrm{E}-12$ & $3 \mathrm{E}-11$ & $7 \mathrm{E}-11$ & $-1 \mathrm{E}-10$ & $-2 \mathrm{E}-10$ & $3 \mathrm{E}-10$ \\
\hline Std. Dev. & $1 \mathrm{E}-02$ & $6 \mathrm{E}-03$ & $5 \mathrm{E}-03$ & $3 \mathrm{E}-03$ & $2 \mathrm{E}-03$ & $2 \mathrm{E}-03$ \\
\hline Max & $6 \mathrm{E}-02$ & $3 \mathrm{E}-02$ & $3 \mathrm{E}-02$ & $2 \mathrm{E}-02$ & 9E-03 & 7E-03 \\
\hline Min & $-5 \mathrm{E}-02$ & $-3 \mathrm{E}-02$ & $-2 \mathrm{E}-02$ & $-1 \mathrm{E}-02$ & $-9 \mathrm{E}-03$ & $-5 \mathrm{E}-03$ \\
\hline Skewness & $6 \mathrm{E}-01$ & 7E-01 & 7E-01 & $6 \mathrm{E}-01$ & $2 \mathrm{E}-01$ & 9E-02 \\
\hline Kurtosis & $7 \mathrm{E}+00$ & $6 \mathrm{E}+00$ & $8 \mathrm{E}+00$ & $7 \mathrm{E}+00$ & $4 \mathrm{E}+00$ & $3 \mathrm{E}+00$ \\
\hline
\end{tabular}


Table 3 (continued)

\section{(e) China}

\begin{tabular}{|c|c|c|c|c|c|c|}
\hline & $D_{i 1}$ & $D_{i 2}$ & $D_{i 3}$ & $D_{i 4}$ & $D_{i 5}$ & $D_{i 6}$ \\
\hline Mean & $6.9 \mathrm{E}-12$ & $-1.7 \mathrm{E}-10$ & $-1.0 \mathrm{E}-10$ & $-1.4 \mathrm{E}-10$ & $2.9 \mathrm{E}-11$ & $1.2 \mathrm{E}-10$ \\
\hline Std. Dev. & $1.4 \mathrm{E}-02$ & $6.8 \mathrm{E}-03$ & 4.4E-03 & $3.0 \mathrm{E}-03$ & 2.7E-03 & 2.7E-03 \\
\hline Max & $6.4 \mathrm{E}-02$ & $3.8 \mathrm{E}-02$ & $1.8 \mathrm{E}-02$ & $1.1 \mathrm{E}-02$ & $1.1 \mathrm{E}-02$ & 9.8E-03 \\
\hline Min & $-5.9 \mathrm{E}-02$ & $-2.5 \mathrm{E}-02$ & $-1.7 \mathrm{E}-02$ & $-8.6 \mathrm{E}-03$ & $-7.5 \mathrm{E}-03$ & $-6.2 \mathrm{E}-03$ \\
\hline Skewness & $4.5 \mathrm{E}-01$ & $6.1 \mathrm{E}-01$ & $4.5 \mathrm{E}-01$ & 4.0E-01 & $6.3 \mathrm{E}-01$ & 7.5E-01 \\
\hline Kurtosis & $5.5 \mathrm{E}+00$ & $5.4 \mathrm{E}+00$ & $5.0 \mathrm{E}+00$ & $3.6 \mathrm{E}+00$ & $4.3 \mathrm{E}+00$ & $5.1 \mathrm{E}+00$ \\
\hline \multicolumn{7}{|c|}{ (f) South Africa } \\
\hline & $D_{i 1}$ & $D_{i 2}$ & $D_{i 3}$ & $D_{i 4}$ & $D_{i 5}$ & $D_{i 6}$ \\
\hline Mean & $-3 \mathrm{E}-12$ & $3 \mathrm{E}-10$ & $1 \mathrm{E}-10$ & $7 \mathrm{E}-11$ & $2 \mathrm{E}-10$ & $2 \mathrm{E}-10$ \\
\hline Std. Dev. & $1 \mathrm{E}-02$ & $6 \mathrm{E}-03$ & $4 \mathrm{E}-03$ & $3 \mathrm{E}-03$ & $3 \mathrm{E}-03$ & $3 \mathrm{E}-03$ \\
\hline Max & $4 \mathrm{E}-02$ & $3 \mathrm{E}-02$ & $3 \mathrm{E}-02$ & $1 \mathrm{E}-02$ & $2 \mathrm{E}-02$ & $1 \mathrm{E}-02$ \\
\hline Min & $-4 \mathrm{E}-02$ & $-3 \mathrm{E}-02$ & $-2 \mathrm{E}-02$ & $-8 \mathrm{E}-03$ & $-1 \mathrm{E}-02$ & $-7 \mathrm{E}-03$ \\
\hline Skewness & $5 \mathrm{E}-01$ & $6 \mathrm{E}-01$ & $6 \mathrm{E}-01$ & $1 \mathrm{E}+00$ & $1 \mathrm{E}+00$ & $1 \mathrm{E}+00$ \\
\hline Kurtosis & $4 \mathrm{E}+00$ & $9 \mathrm{E}+00$ & $1 \mathrm{E}+01$ & $7 \mathrm{E}+00$ & $1 \mathrm{E}+01$ & $8 \mathrm{E}+00$ \\
\hline
\end{tabular}

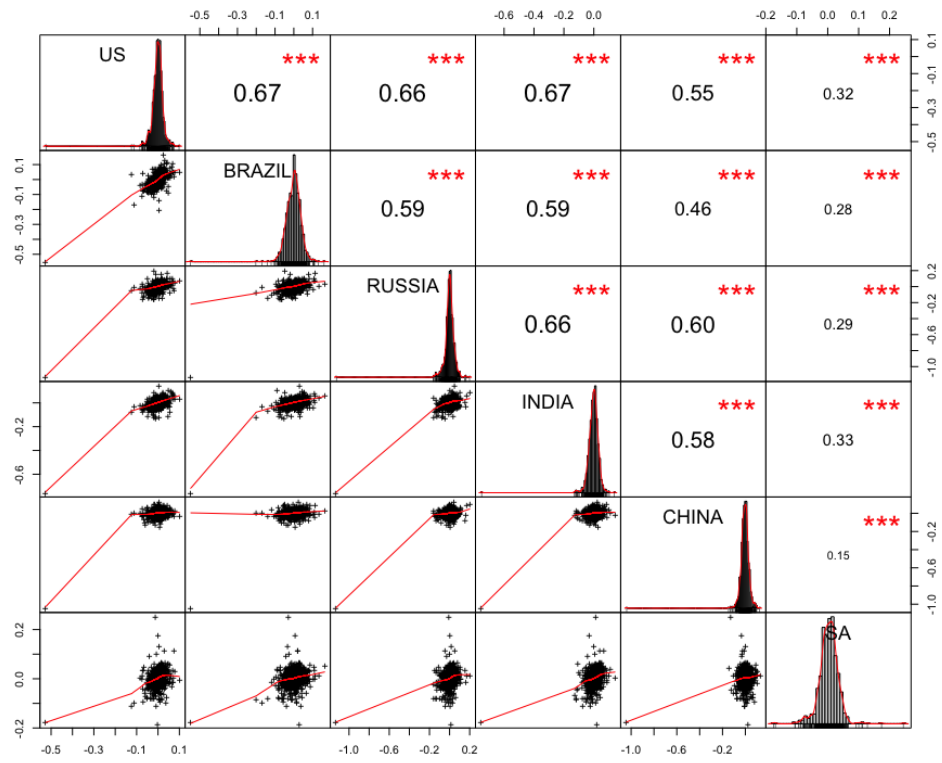

Figure 1. Scatter plots, histograms and linear correlations.

Note: $\left[{ }^{* * *}\right]$ represents that linear correlations are significant at $1 \%$ level of significance. 


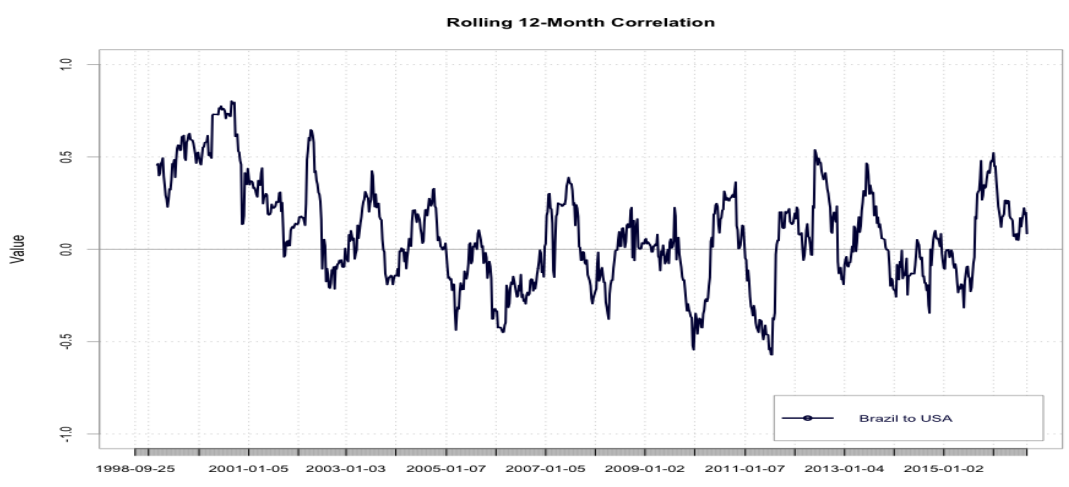

(a) Brazil

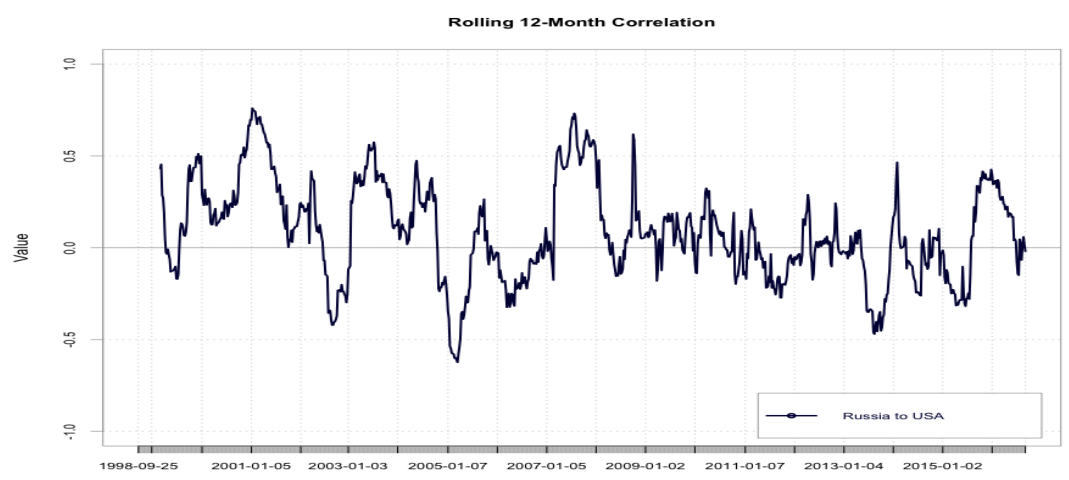

(b) Russia

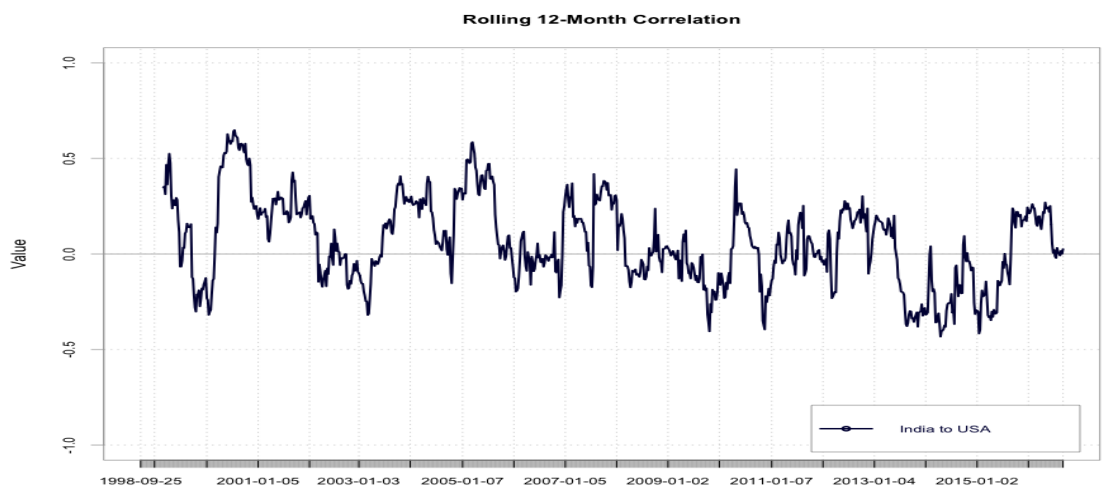

(c) India 


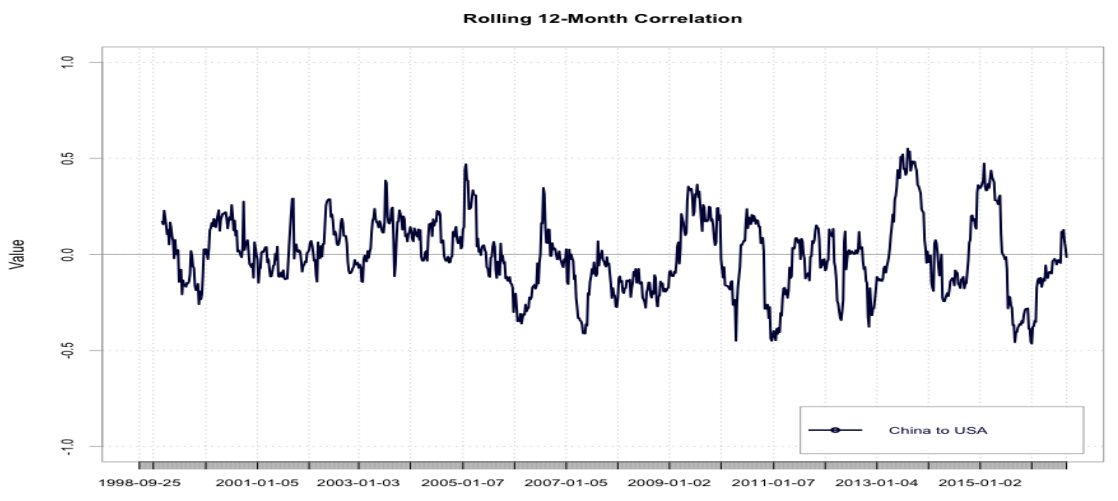

(d) China

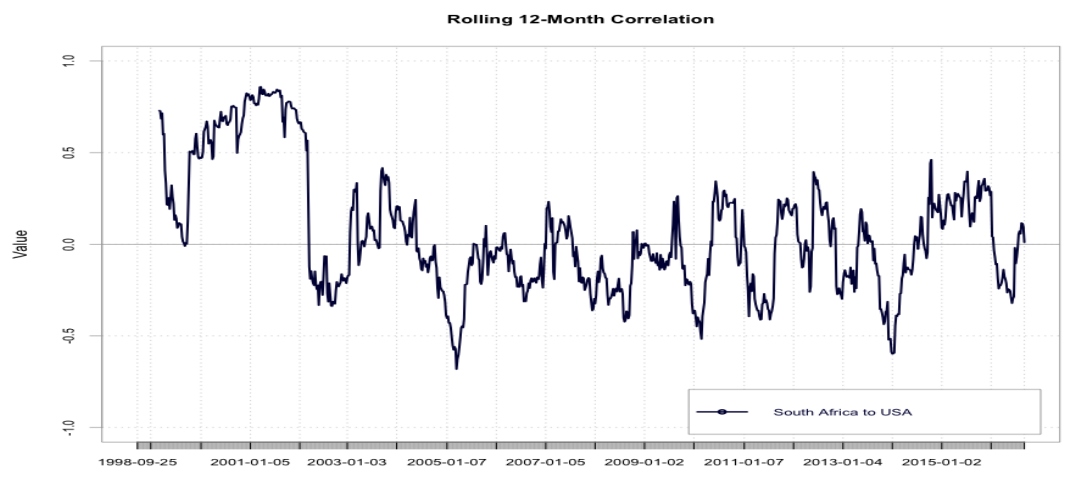

(e) South Africa

Figure 2. 12-months rolling correlations of BRICS countries with respect to the US. Note: The horizontal axis shows the timeline, whereas the vertical axis represents the value of correlation coefficient.

Figure 2 exhibits the 12-months rolling correlations of BRICS countries with the US. Overall, all the countries depict a weak mean-reverting propensity. A higher degrees of positive correlation is evident for all the countries till the year 2002, China being the only exception. During GFC, around the period of 2008 the correlations tend to drop for all the countries. In the post-GFC era, the upper and lower bound of correlations appear marginally restrictive as compared to pre GFC period, except for China. China appears to be more correlated with the US in the post-GFC era, particularly after 2013. 


\section{MAIN RESULTS}

This section discusses the results in detail. The first sub-section describes the results of the wavelet coherence analysis. The second segment explains the results of wavelet correlation followed by third sub-section of wavelet multiple correlation.

\section{Wavelet Coherence Analysis}

Figure 3 exhibits the pairwise wavelet coherence maps in the form of a contour plot. The coherence maps ease the understanding of changing behaviour in the linkages between the stock market returns of BRICS and the US over the timefrequency frame. The vertical axis on the other hand indicates the frequencies from low (256 weeks) to high (4 weeks) range in weeks, whereas the horizontal axis shows the timeline. The red zones indicate strong levels of co-movement while the blue zones are representative of weaker co-movement levels. The black line delimits the area at statistically significant level of 5\%. Arrows in the coherence maps designate the lead/lag relationship in the time-frequency space of a continuous wavelet transform framework. The left-tailed $(\rightarrow) /$ righttailed $(\leftarrow)$ arrows show the two time-series under consideration are in-phase/ anti-phase respectively. The in-phase and anti-phase phenomenon depicts positive and negative co-movements respectively. The upward ( $\uparrow$ ), right-upward $(\nearrow)$ and left-downward $(\measuredangle)$ arrows represent the first time series leads the second one. Similarly, the downward $(\downarrow)$, right-downward $(\searrow)$ and left-upward $(\searrow)$ arrows indicate the first time-series tends to follows the lead of the second series (Jiang, Nie, \& Monginsidi, 2017; Vacha \& Barunik, 2012). The blackish translucent area in the coherence maps represents the cone of influence i.e. the region which is affected by edge effects and analysis of which falls out of statistical significance.

The coherence maps in Figure 3 illustrates that co-movements in relatively lower frequencies are more significant especially during the period of economic turbulence. This result is evident for all other constituents of BRICS, which support the contagion hypothesis. Brazil [Figure 3(a)] and South Africa [Figure 3(e)] appears to be most coherent with the US. Whereas, China [Figure 3(d)] shows the least co-movement with the US of others in BRICS group except for during the crisis period.

The phases as indicated by arrows are mostly left-tailed $(\rightarrow)$, which implies a positive correlation between the pairs of time-series. Further, an interesting phenomenon is observed regarding the lead/lag relationship. The arrows point right downwards $(\searrow$ ) for all constituents around the period of crisis in 2008, which designate that BRICS constituents lead the US index returns series 
for a small interval of time. The causal reason may be attributed to the fall in index returns of BRICS countries at a faster rate than the US. However, the trend decays shortly.

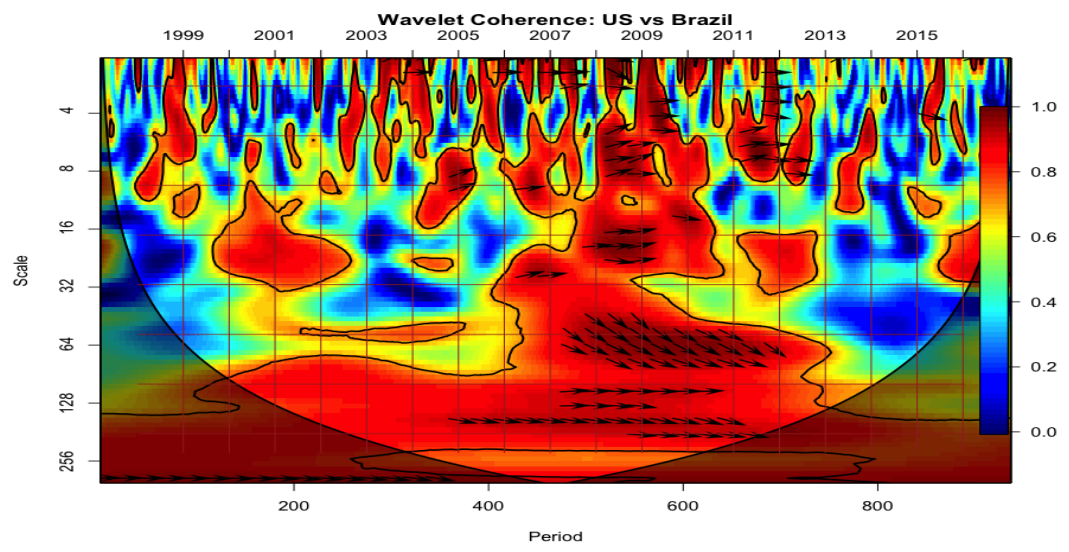

(a) Brazil

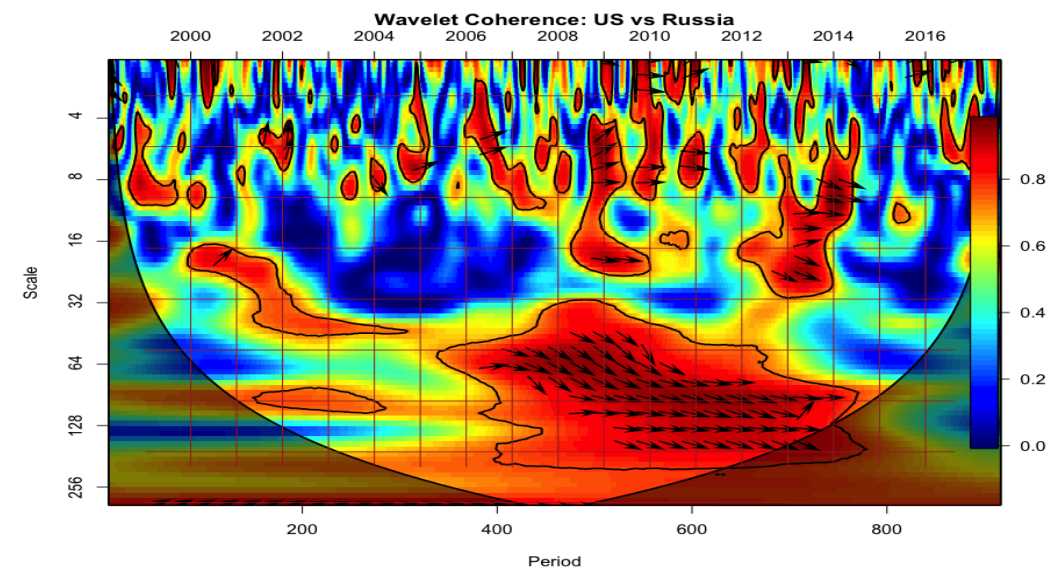

(b) Russia 


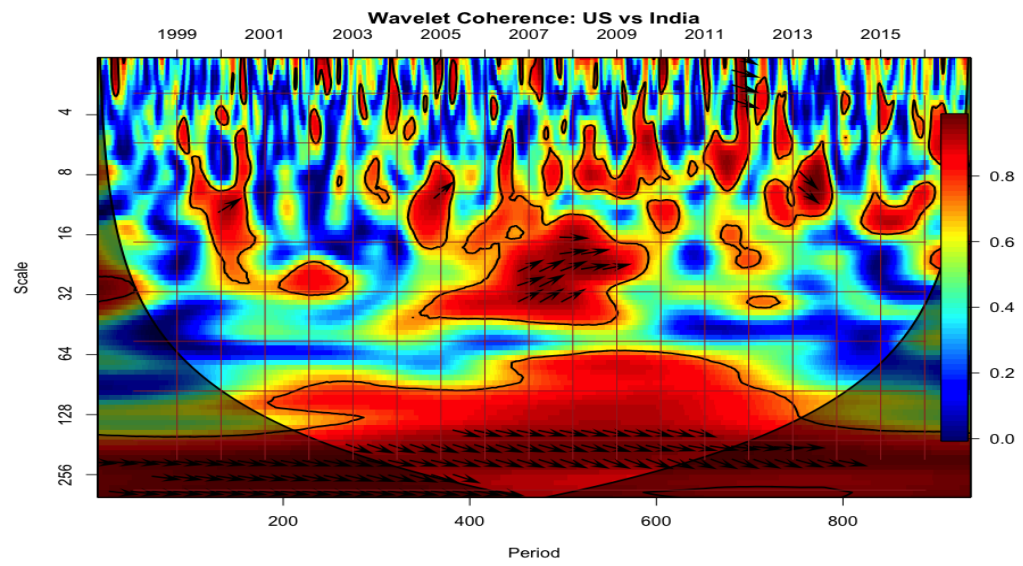

(c) India

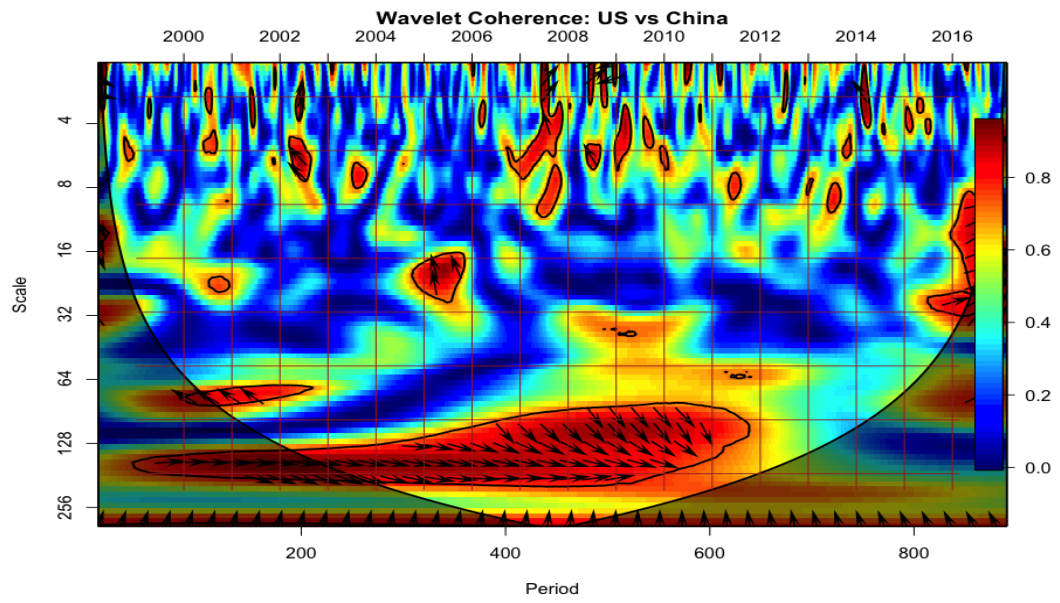

(d) China 


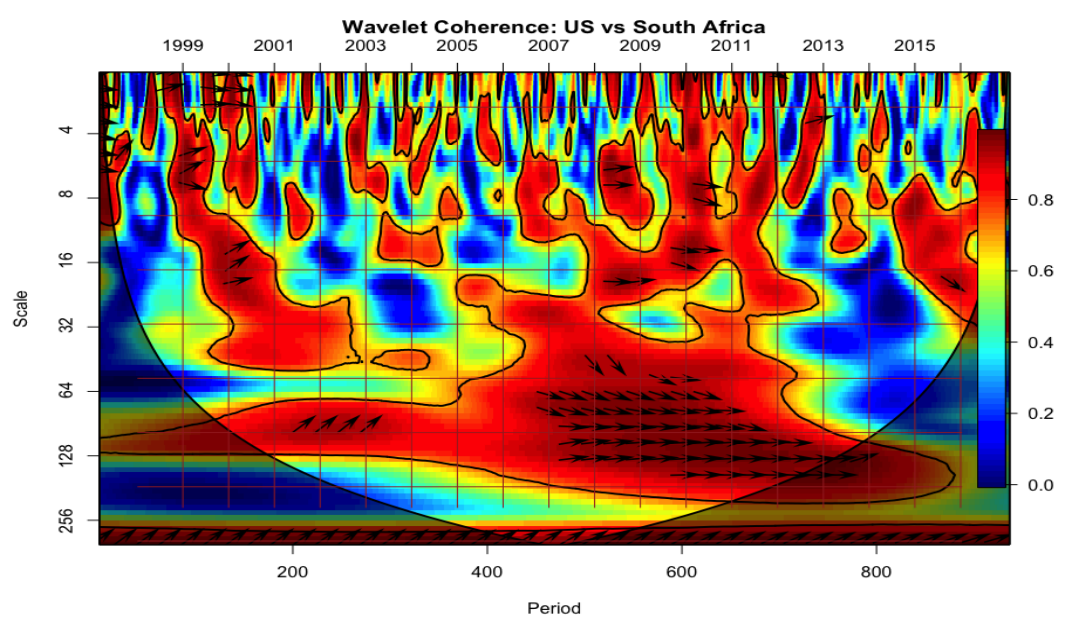

(e) South Africa

Figure 3. Wavelet coherence between the US and BRICS.

Note: The 5\% significance level estimated from Monte Carlo Simulations is designated by the black contour. The red (blue) colours signify region with high (low) coherency. The legend (on the right of the maps) shows the power of coherence coefficients.

\section{Wavelet Correlation Analysis}

Figure 4 exhibits the pairwise wavelet correlations. The information regarding correlations at different timescales is of paramount importance since it has practical implications for portfolio diversifications. Figure 4(a) shows that Brazil's correlations with the US tend to fall at the longest timescale in the postGFC era. Similar phenomenon may be noted for India.

Russia and China depict higher correlations in the post-GFC era, whereas the correlation of South Africa with the US appears relatively stable. Table 4 presents the values of wavelet correlation coefficients and upperlower confidence interval bounds. Table 5 presents the results for independent samples $t$-tests performed on the wavelet correlation coefficients to validate the differences in correlations in the pre and post-GFC era statistically. The results show the correlation patterns have changed significantly for Russia and China. Undoubtedly, correlations are time varying and changes may also be observed for other BRICS constituents, but they appear to be statistically insignificant. 


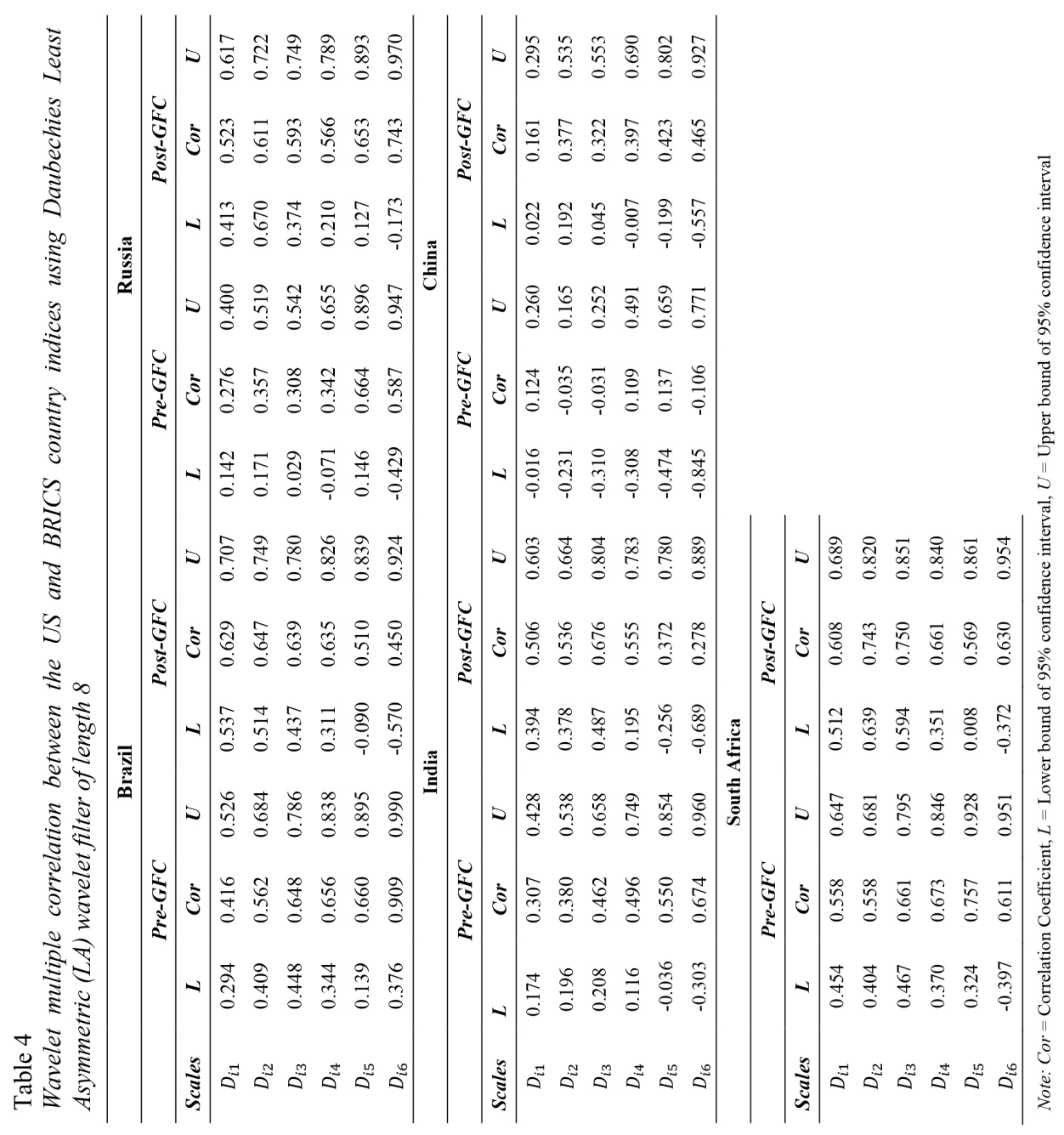



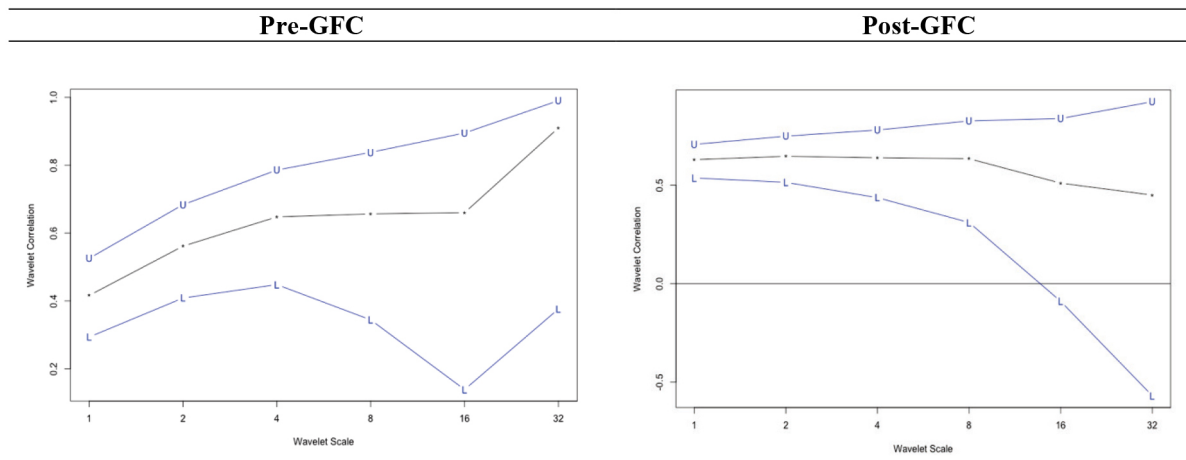

(a) US-Brazil
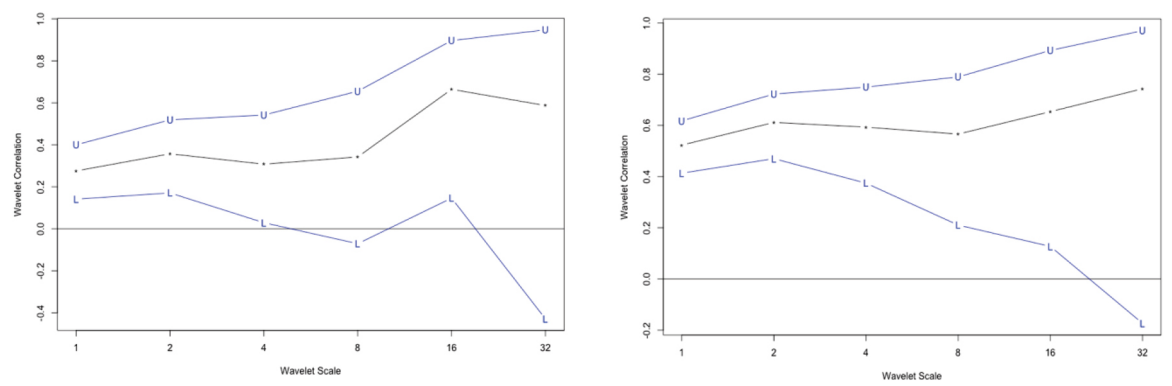

(b) US-Russia
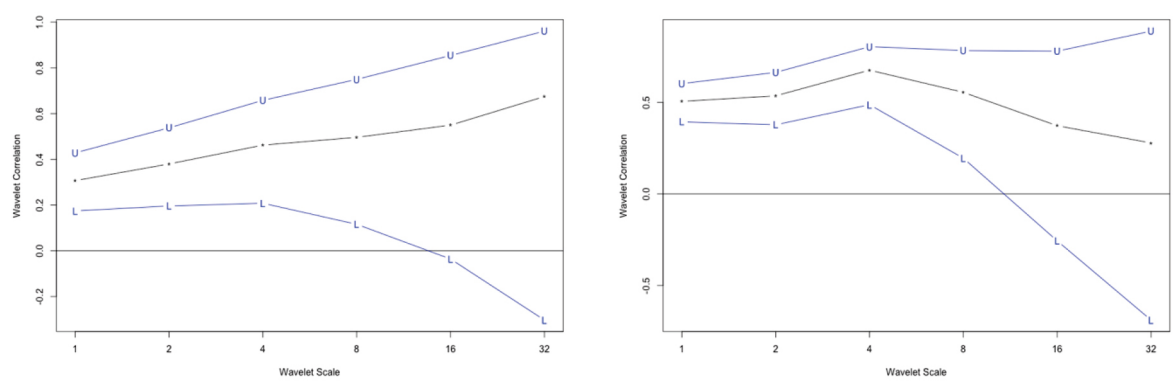

(c) US-India 

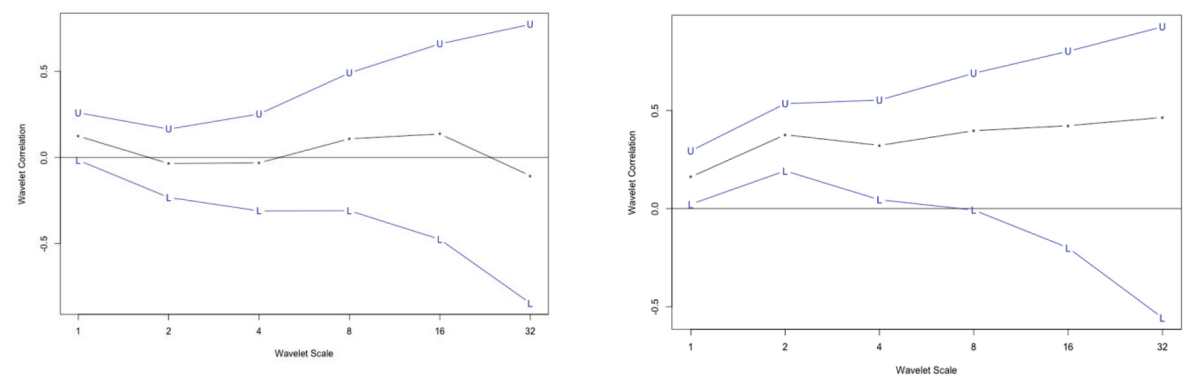

(d) US-China
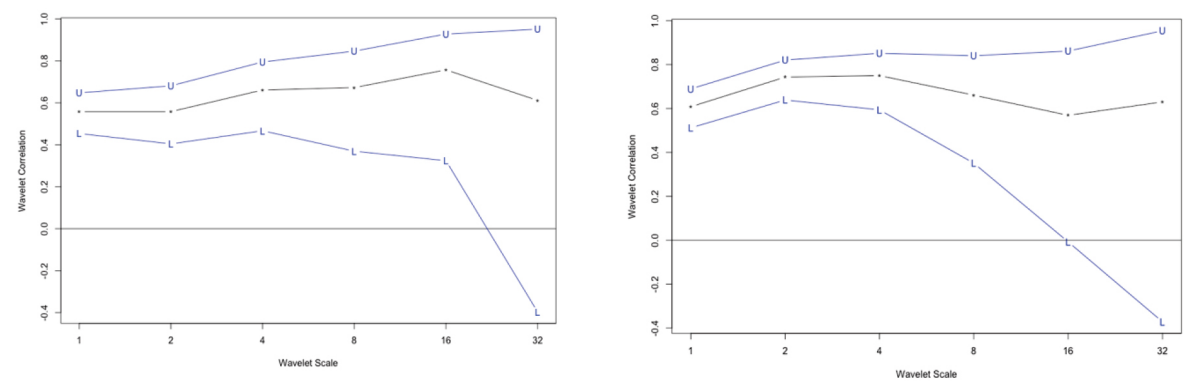

(e) US-South Africa

Figure 4. Wavelet correlation between the US and BRICS countries.

Note: The blue lines correspond to the upper and lower bounds of the $95 \%$ confidence interval. The wavelet scales represented in the $\mathrm{x}$-axis represent time-periods, which corresponds to $2^{\mathrm{j}}$, where superscript represents the scale.

Table 5

Independent sample t-test

\begin{tabular}{lcc}
\hline & $t$-statistics & $p$-value \\
\hline Brazil & 0.768 & 0.460 \\
Russia & -2.637 & $0.033^{* *}$ \\
India & -0.115 & 0.911 \\
China & -5.345 & $0.000^{* * *}$ \\
South Africa & -0.550 & 0.594 \\
\hline
\end{tabular}

Note: $\left[{ }^{* *}\right],[* *]$ represents $1 \%$ and $5 \%$ level of significance respectively.

\section{Wavelet Multiple Correlation Analysis}

The wavelet multiple correlation analysis is performed to unveil the extent to which the BRICS markets are correlated among themselves. Figure 5 clearly shows an increasing correlation at increasing scales signifying stronger co- 
movements in the longer run. The WMC shows a value of over $0.5-0.7$ and tends closer to 0.9 in both pre- and post-GFC era (Table 6). Such strong co-movements entail a state near to perfect integration. A state of perfect integration may limit the benefits of arbitrage and portfolio diversification.

Table 6

Wavelet multiple correlation among BRICS country indices using Daubechies Least Asymmetric (LA) wavelet filter of length 8

\begin{tabular}{lcccccc}
\hline \multirow{2}{*}{ Scales } & \multicolumn{3}{c}{ Pre-GFC } & \multicolumn{3}{c}{ Post-GFC } \\
\cline { 2 - 7 } & $\mathrm{L}$ & Cor & $\mathrm{U}$ & $\mathrm{L}$ & Cor & $\mathrm{U}$ \\
\hline$D_{i 1}$ & 0.449 & 0.554 & 0.644 & 0.623 & 0.702 & 0.766 \\
$D_{i 2}$ & 0.507 & 0.641 & 0.744 & 0.621 & 0.729 & 0.810 \\
$D_{i 3}$ & 0.507 & 0.690 & 0.813 & 0.588 & 0.746 & 0.849 \\
$D_{i 4}$ & 0.745 & 0.760 & 0.514 & 0.479 & 0.739 & 0.880 \\
$D_{i 5}$ & 0.605 & 0.875 & 0.965 & 0.449 & 0.813 & 0.946 \\
$D_{i 6}$ & 0.320 & 0.898 & 0.988 & 0.235 & 0.879 & 0.987 \\
\hline
\end{tabular}

Note: Cor $=$ Correlation Coefficient, $L=$ Lower bound of $95 \%$ confidence interval, $U=$ Upper bound of $95 \%$ confidence interval

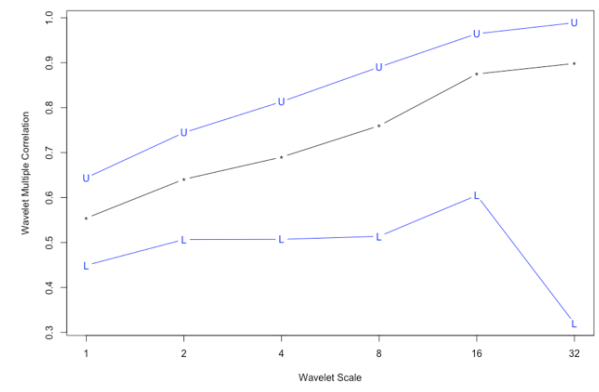

(a) Pre-GFC

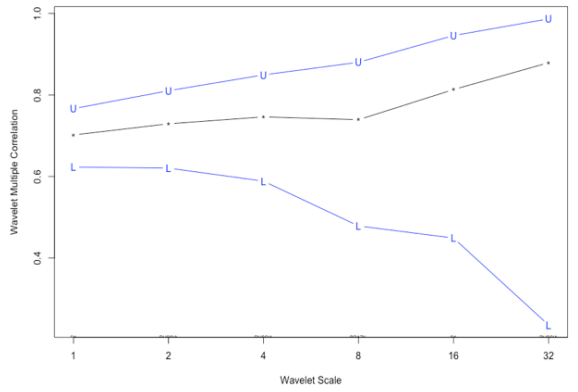

(b) Post-GFC

Figure 5. Wavelet multiple correlation among BRICS

In order to check whether correlations among the BRICS markets changed after the GFC, independent sample t-test is performed (see Table 7). The statistically insignificant $p$-value shows there is no evidence of significant change in correlations among the BRICS markets. 
Table 7

Independent sample t-test

\begin{tabular}{lcc}
\hline & $t$-statistics & $p$-value \\
\hline BRICS & -0.550 & 0.594 \\
\hline
\end{tabular}

\section{CONCLUSIONS}

Portfolio managers, in general, are more attentive towards the co-movement phenomena at higher frequencies (short-run co-movements), whereas the interest of investors lies in co-movements at lower frequencies (long-run comovements) (Aloui \& Hkiri, 2014). Using wavelet analysis both short and long run co-movements in BRICS countries with respect to the US is identified, which satisfies the interest of both portfolio managers and investors. The results show some significant co-movements at both higher and lower frequencies. However, co-movements in the long run are more significant. Further, the signs of contagion around the financial crisis in the year 2008 are precisely observable. There exists a high correlation of returns, which may limit the extent of diversification benefit. However, investing in BRICS portfolio can yield some diversification benefits in the medium run on account of relatively lower co-movements. Our findings are somewhat consistent with Lehkonen and Heimonen (2014). Thus, it may be inferred BRICS as an identical group of emerging and geographically diversified economies may offer some diversification benefits despite of considerably higher correlations. One possible reason of higher correlation may be the presence three major emerging Asian economies in BRICS group i.e. Russia, India and China. As a response to the primitive question of interest in this study, i.e. whether co-movements changed considerably after GFC, we find China and Russia significantly differ in their correlation dynamics with the US in the post-GFC era. Other markets do not depict much change in correlation pattern.

\section{NOTES}

1. For a detailed discussion on methodology refer (Andrieş et al., 2016; Ko \& Lee, 2015; Kumar Tiwari, Billah Dar, Bhanja, \& Shah, 2013; Vacha \& Barunik, 2012).

2. A structural break test of Hsu (1979) is also conducted to validate the structural change, which shows a major structural break date in September 2008. 


\section{REFERENCES}

Aloui, C., \& Hkiri, B. (2014). Co-movements of GCC emerging stock markets : New evidence from wavelet coherence analysis. Economic Modelling, 36, 421-431. https://doi.org/10.1016/j.econmod.2013.09.043

Andrieş, A. M., Ihnatov, I., \& Tiwari, A. K. (2016). Comovement of exchange rates: A wavelet analysis. Emerging Markets Finance and Trade, 52(3), 574-588. https:// doi.org/10.1080/1540496X.2014.998563

Arouri, M. E. H., Bellalah, M., \& Nguyen, D. K. (2010). The comovements in international stock markets: New evidence from Latin American emerging countries. Applied Economics Letters, 17(13), 1323-1328. https://doi. org/10.1080/13504850902967449

Ayuso, J., \& Blanco, R. (2001). Has financial market integration increased during the nineties? Journal of International Financial Markets, Institutions and Money, 11(3), 265-287.

Baruník, J., Vácha, L., \& Krištoufek, L. (2011). Comovement of Central European stock markets using wavelet coherence: Evidence from high-frequency data. IES Working Paper (22/2011), 1-19. Retrieved from http:/www.econstor.eu/ handle/10419/83377

Bekaert, G., \& Harvey, C. R. (1997). Emerging equity market volatility. Journal of Financial Economics, 43(1), 29-77. https://doi.org/10.1016/S0304-405X(96)00889-6

Bekiros, S. D. (2014). Contagion, decoupling and the spillover effects of the US financial crisis: Evidence from the BRIC markets. International Review of Financial Analysis, 33, 58-69.

Berben, R.-P., \& Jansen, W. J. (2005). Comovement in international equity markets: A sectoral view. Journal of International Money and Finance, 24(5), 832-857.

Bianconi, M., Yoshino, J. A., \& De Sousa, M. O. M. (2013). BRIC and the US financial crisis: An empirical investigation of stock and bond markets. Emerging Markets Review, 14, 76-109.

Boako, G., \& Alagidede, P. (2017). Co-movement of Africa's equity markets: Regional and global analysis in the frequency-time domains. Physica A: Statistical Mechanics and Its Applications, 468, 359-380. http://doi.org/10.1016/j.physa.2016.10.088

Brooks, R., \& Del Negro, M. (2004). The rise in comovement across national stock markets: Market integration or IT bubble? Journal of Empirical Finance, 11(5), 659-680.

Chan, K. C., Gup, B. E., \& Pan, M. (1997). International stock market efficiency and integration: A study of eighteen nations. Journal of Business Finance \& Accounting, 24(6), 803-813.

Das, D., Kannadhasan, M., \& Goyal, V. (2016). Wavelet analysis of stock return comovements in emerging markets. Retrieved from https://ssrn.com/ abstract $=2877986$

Das, D., Kannadhasan, M., Tiwari, A. K., \& Al-Yahyaee, K. H. (2018). Has co-movement dynamics in emerging stock markets changed after global financial crisis? New evidence from wavelet analysis. Applied Economics Letters, 1-7. https://doi.org/ 10.1080/13504851.2018.1430307 
Dewandaru, G., Masih, R., \& Masih, A. M. M. (2016). Contagion and interdependence across Asia-Pacific equity markets: An analysis based on multi-horizon discrete and continuous wavelet transformations. International Review of Economics \& Finance, 43, 363-377.

Dewandaru, G., Masih, R., \& Masih, M. (2017). Regional spillovers across transitioning emerging and frontier equity markets: A multi-time scale wavelet analysis. Economic Modelling, 65, 30-40.

Dima, B., Dima, Ş. M., \& Barna, F. (2014). A wavelet analysis of capital markets' integration in Latin America. Applied Economics, 47(10), 1019-1036. https://doi. org/10.1080/00036846.2014.987917

el Alaoui, A. O., Dewandaru, G., Rosly, S. A., \& Masih, M. (2015). Linkages and comovement between international stock market returns: Case of Dow Jones Islamic Dubai Financial Market index. Journal of International Financial Markets, Institutions and Money, 36, 53-70.

Fernández-Macho, J. (2012). Wavelet multiple correlation and cross-correlation: A multiscale analysis of Eurozone stock markets. Physica A: Statistical Mechanics and Its Applications, 391(4), 1097-1104. https://doi.org/10.1016/j. physa.2011.11.002

Francis, B. B., Hasan, I., \& Sun, X. (2008). Financial market integration and the value of global diversification: Evidence for US acquirers in cross-border mergers and acquisitions. Journal of Banking and Finance, 32(8), 1522-1540. http://doi. org/10.1016/j.jbankfin.2007.10.013

Gklezakou, T., \& Mylonakis, J. (2009). Interdependence of the developing stock markets, before and during the economic crisis: The case of South Europe. Journal of Money, Investment and Banking, 11, 70-78.

Graham, M., \& Nikkinen, J. (2011). Co-movement of the Finnish and international stock markets: A wavelet analysis. The European Journal of Finance, 17(5-6), 409425.

Graham, M., Kiviaho, J., \& Nikkinen, J. (2012). Integration of 22 emerging stock markets: A three-dimensional analysis. Global Finance Journal, 23(1), 34-47. https://doi. org/10.1016/j.gfj.2012.01.003

Gupta, R., \& Donleavy, G. D. (2009). Benefits of diversifying investments into emerging markets with time-varying correlations: An Australian perspective. Journal of Multinational Financial Management, 19(2), 160-177.

Hargis, K., \& Mei, J. (2006). Is country diversification better than industry diversification? European Financial Management, 12(3), 319-340.

Hasan, I., Schmiedel, H., \& Song, L. (2012). Growth strategies and value creation: What works best for stock exchanges? Financial Review, 47(3), 469-499.

Hsu, D. A. (1979). Detecting shifts of parameter in gamma sequences with applications to stock price and air traffic flow analysis. Journal of the American Statistical Association, 74(365), 31-40. https://doi.org/10.1080/01621459.1979.10481604

Jiang, Y., Nie, H., \& Monginsidi, J. Y. (2017). Co-movement of ASEAN stock markets: New evidence from wavelet and VMD-based copula tests. Economic Modelling, 64, 384-398. 
Karolyi, G. A., \& Stulz, R. M. (1996). Why do markets move together? An investigation of U.S.-Japan stock return comovements. Journal of Finance, 51(3), 951-986. https://doi.org/10.2307/2329228

Karolyi, G. A. \& Stulz, R. M. (2003). Are financial assets priced locally or globally? In G.M. Constantinides \& M. Harris \& R. M. Stulz (ed.), Handbook of the economics of finance (vol. 1, pp. 975-1020). Amsterdam, The Netherlands: Elsevier.

Kiviaho, J., Nikkinen, J., Piljak, V., \& Rothovius, T. (2014). The co-movement dynamics of European Frontier Stock Markets. European Financial Management, 20(3), 574-595. https://doi.org/10.1111/j.1468-036X.2012.00646.x

Ko, J., \& Lee, C. (2015). International economic policy uncertainty and stock prices: Wavelet approach. Economics Letters (Vol. 134). Amsterdam: Elsevier B.V.

Kumar Tiwari, A., Billah Dar, A., Bhanja, N., \& Shah, A. (2013). Stock market integration in Asian countries: Evidence from Wavelet multiple correlations. Journal of Economic Integration, 28(3), 441-456. http://doi.org/10.11130/jei.2013.28.3.441

Lehkonen, H., \& Heimonen, K. (2014). Timescale-dependent stock market comovement: BRICs vs. developed markets. Journal of Empirical Finance, 28, 90-103. http:// doi.org/10.1016/j.jempfin.2014.06.002

Longin, F., \& Solnik, B. (1995). Is the correlation in international equity returns constant: 1960-1990? Journal of International Money and Finance, 14(1), 3-26. http://doi. org/10.1016/0261-5606(94)00001-H

Masih, M., Alzahrani, M., \& Al-Titi, O. (2010). Systematic risk and time scales: New evidence from an application of wavelet approach to the emerging Gulf stock markets. International Review of Financial Analysis, 19(1), 10-18.

Najeeb, S. F., Bacha, O., \& Masih, M. (2015). Does heterogeneity in investment horizons affect portfolio diversification? Some insights using M-GARCH-DCC and wavelet correlation analysis. Emerging Markets Finance and Trade, 51(1), 188-208.

Pukthuanthong, K., \& Roll, R. (2009). Global market integration: An alternative measure and its application. Journal of Financial Economics, 94(2), 214-232.

Ranta, M. (2013). Contagion among major world markets: A wavelet approach. International Journal of Managerial Finance, 9(2), 133-149. http://doi. org/10.1108/17439131311307556

Reboredo, J. C., \& Rivera-Castro, M. A. (2013). A wavelet decomposition approach to crude oil price and exchange rate dependence. Economic Modelling, 32(1), 42-57.

Rua, A., \& Nunes, L. C. (2009). International comovement of stock market returns: A wavelet analysis. Journal of Empirical Finance, 16(4), 632-639. http://doi. org/10.1016/j.jempfin.2009.02.002

Saiti, B. \& Masih, M. (2014). the co-movement of selective conventional and Islamic stock markets in East Asia: Is there any impact on shariah compliant equity investment in China? MPRA Paper 56992, University Library of Munich, Germany.

Schwebach, R. G., Olienyk, J. P., \& Zumwalt, J. K. (2002). The impact of financial crises on international diversification. Global Finance Journal, 13(2), 147-161.

Sharma, A., \& Seth, N. (2012). Literature review of stock market integration: A global perspective. Qualitative Research in Financial Markets, 4(1), 84-122. http://doi. org/10.1108/17554171211213568 
Syriopoulos, T. (2007). Dynamic linkages between emerging European and developed stock markets: Has the EMU any impact? International Review of Financial Analysis, 16(1), 41-60.

Syriopoulos, T., \& Roumpis, E. (2009). Dynamic correlations and volatility effects in the Balkan equity markets. Journal of International Financial Markets, Institutions and Money, 19(4), 565-587.

Vacha, L., \& Barunik, J. (2012). Co-movement of energy commodities revisited: Evidence from wavelet coherence analysis. Energy Economics, 34(1), 241-247. http://doi. org/10.1016/j.eneco.2011.10.007

Yang, J., Kolari, J. W., \& Min, I. (2003). Stock market integration and financial crises: The case of Asia. Applied Financial Economics, 13(7), 477-486. http://doi. org/10.1080/09603100210161965

Zhang, B., \& Li, X.-M. (2014). Has there been any change in the comovement between the Chinese and US stock markets? International Review of Economics \& Finance, 29, 525-536.

Zhang, B., Li, X., \& Yu, H. (2013). Has recent financial crisis changed permanently the correlations between BRICS and developed stock markets? North American Journal of Economics and Finance, 26, 725-738. http://doi.org/10.1016/j. najef.2013.05.003 
M. Kannadhasan and Debojyoti Das 